\title{
Hemofilter with Adsorptive Capacities: Case Report Series
}

\author{
Ling Zhang $^{\mathrm{a}}$ Gloria Kai Yan Tang ${ }^{\mathrm{b}}$ Songqiao Liuc Jing Cai ${ }^{\mathrm{d}}$ Wai Ming Chan ${ }^{\mathrm{b}}$ \\ Yi Yang $^{c}$ Ping Chang ${ }^{d}$ Tiantian Wei $^{a}$ Xinyu Liu ${ }^{e}$ Qiang Yao ${ }^{e}$ Minmin Wang ${ }^{f}$ \\ Mark R. Marshall ${ }^{f}$ \\ a Division of Nephrology, West China Hospital of Sichuan University, Chengdu, China; ${ }^{b}$ Adult Intensive Care Unit, \\ Queen Mary Hospital, Hong Kong, China; ' Department of Critical Care Medicine, Nanjing Zhongda Hospital, \\ Southeast University, Nanjing, China; ${ }^{\mathrm{d}}$ Department of Intensive Care Unit, Zhujiang Hospital, Southern Medical \\ University, Guangzhou, China; ${ }^{e}$ Medical Affairs, Baxter China Ltd, Shanghai, China; ${ }^{f}$ Medical Affairs, Baxter \\ Healthcare (Asia) Pte Ltd, Singapore, Singapore
}

\section{Keywords}

Sepsis · Acute kidney injury · Hemofiltration · Renal replacement therapy . Case report

\section{Abstract}

Background: oXiris is a blood purification product that has been launched recently in China. In addition to renal function support and fluid management capabilities, it can also adsorb cytokines and endotoxins. This may complement standard treatment for septic acute kidney injury (AKI) patients to control the amplitude of systemic inflammatory response responsible for acute tissue and organ damage. Objectives of our study are to elucidate characteristics of septic AKI patients who respond to treatment with oXiris and to describe the performance of oXiris through patient cases in the absence of large randomized trials on clinical use of oXiris for septic AKI patients in China. Summary: Here, we present 4 cases managed in intensive care units of major hospitals in China. Key practical aspects from an expert meeting discussing these cases have been included as guidance for the use of oXiris in septic AKI patients. Key Messages: Based on the experience gathered from 4 cases, oXiris should be used early in the treatment of septic AKI patients as an adjuvant therapy with good infection source control. It should not be used to delay or replace infection source control. These cases also demonstrated that patients with high risk of bleeding can use oXiris without additional anticoagulation for up to $36 \mathrm{~h}$ without implications on serum protein levels and platelet count. Short of definitive biomarkers to gauge the ideal blood purification initiation and discontinuation time for septic AKI patients, clinical judgment is key to determining optimal use of oXiris in septic AKI patients.

(c) 2019 The Author(s)
Published by S. Karger AG, Basel

\section{Introduction}

Sepsis is the most common cause of acute kidney injury (AKI) in critically ill patients and is found in almost $50 \%$ of patients with severe AKI in the intensive care unit (ICU) $[1,2]$. Continuous renal replacement therapy

\section{L.Z., G.K.Y.T., S.L., and J.C. contributed equally to this work.}


(CRRT) is recommended for management of septic AKI patients, particularly those with hemodynamic instability or fluid overload [3]. However, detailed guidance on CRRT for these patients has not been established, partly owing to incomplete understanding of the pathophysiology of sepsis beyond the involvement of inflammatory mediators.

oXiris is a next-generation extracorporeal blood purification (EBP) device that employs diffusive, convective, and adsorptive techniques for CRRT and endotoxin and cytokine elimination [4-9], while reducing membrane thrombogenicity via local inhibition of coagulation $[4,5]$. In vitro filtration and observational studies have shown that oXiris removes a wide spectrum of immune response mediators, notably, almost $100 \%$ of interleukin-10 and approximately $90 \%$ of interleukin-6, high-mobility group box 1 protein, and tumor necrosis factor- $\alpha$ [10]. Endotoxin adsorption is viewed as an innovative approach to support standard sepsis treatment by controlling the degree of systemic inflammatory response that causes acute tissue and organ damage in sepsis [11-13].

Although oXiris has been approved for use in Europe for some years, it has only been launched recently in China, with approval from the China Food and Drug Administration for use in providing continuous fluid management and renal replacement therapies in patients with acute renal failure and/or fluid overload [5]; as of January $17,2018,78$ sets of oXiris have been used to treat 29 patients in mainland China [14]. However, owing to the paucity of data in China, there are still many uncertainties around the clinical application of oXiris, particularly in sepsis management. In the absence of large randomized trials in Asian patients, case studies and observational studies provide valuable data to inform clinical practice and trial design.

Here, we present 4 such cases from Tier 1 hospitals in China, including Queen Mary Hospital, West China Hospital of Sichuan University, Nanjing Zhongda Hospital of Southern Medical University, and Zhujiang Hospital of Southern Medical University. Practical aspects that were discussed at an expert meeting are included as guidance for use of oXiris in septic AKI patients.

\section{Case Descriptions}

Case 1

A 66-year-old man presented on March 28, 2017, with a 10-day history of pain and swelling with blister formation on the left leg after hitting his knee against a metal railing. Bedside aspiration of the blister fluid revealed Gram-positive cocci in clusters, and a pro- visional diagnosis of necrotizing fasciitis was made. An emergency through-knee amputation of the left leg was performed on the same day, after which he was put on mechanical ventilation and transferred to the ICU. He received norepinephrine at an infusion rate of $0.9 \mu \mathrm{g} / \mathrm{kg} / \mathrm{min}$. Multiorgan failure with anuric AKI ensued. Blood tests showed creatinine $289 \mu \mathrm{mol} / \mathrm{L}$, potassium $3.9 \mathrm{mmol} / \mathrm{L}$, creatine kinase 1,637 U/L, base excess $-8 \mathrm{mEq} / \mathrm{L}$, lactate $8.1 \mathrm{mmol} / \mathrm{L}$, international normalized ratio 1.4 , and leukocyte count $1.7 \times 10^{9} / \mathrm{L}$.

Continuous venovenous hemofiltration $(\mathrm{CVVH})$ using the oXiris hemofilter without additional anticoagulant was initiated $2 \mathrm{~h}$ after admission to the ICU (Table 1; Appendix 1). The CVVH was stopped after $16 \mathrm{~h}$ because of the need for operation for further debridement. Upon termination of $\mathrm{CVVH}$ with oXiris, the norepinephrine dose was significantly reduced to $0.3 \mu \mathrm{g} / \mathrm{kg} / \mathrm{min}$, lactate decreased to $4.9 \mathrm{mmol} / \mathrm{L}$, and urine output was maintained at $30-50 \mathrm{~mL} / \mathrm{h}$.

The infection had spread progressively despite broad-spectrum antibiotics and initial debridement. An emergency left hip disarticulation was performed on March 30, and a below-knee amputation of the right leg was performed on March 31. Intraoperative tissue specimen and blood culture revealed infection with multidrug-resistant Acinetobacter baumannii. On April 2, he developed blistering over the abdominal wall and refractory shock, requiring escalating doses of norepinephrine. His family refused further surgical debridement or amputation. He succumbed on April 4.

Case 2

A 51-year-old man suffering from upper abdominal discomfort for over a year and an abdominal mass for over 2 months was admitted on September 12, 2017. Preoperative ultrasound revealed an abdominal mass with gastric fistula. Abdominal tumor resection, partial intestinal resection and anastomosis, enterolysis, and cholecystectomy were performed with exploratory laparotomy, and severe abdominal adhesions were noted intraoperatively. Two days later, his condition worsened and he was diagnosed with septic shock, multiple organ dysfunction syndrome (MODS), myelosuppression, and hypoproteinemia. His blood pressure decreased to $70 / 40 \mathrm{~mm} \mathrm{Hg}$, with fluid overload of more than $12 \mathrm{~L}$. He was given norepinephrine, red blood cell and plasma transfusion, mechanical ventilation, a broad-spectrum antibiotic, and rapid rehydration.

A second exploratory laparotomy revealed build-up of pus and dark fluid in the peritoneum, a $1 \times 1 \mathrm{~cm}$ ulcer perforation on the anterior wall of the greater gastric curvature, and the greater omentum was ischemic, edematous, and necrotic. Partial resection of the stomach with further enterolysis, greater omentum resection, and excision of accessory spleen was performed. Severe edema and sporadic petechia, chemosis of the conjunctiva, and peripheral cyanosis were noted intraoperatively. The abdominal wound remained unclosed with the presence of exudate. Urine was produced at a rate of $5-10 \mathrm{~mL} / \mathrm{h}$ with a dark color.

Routine CRRT therapy was initiated on September 15, and a broad-spectrum antibiotic, amikacin, and caspofungin were prescribed. After 2 days, his conditions worsened with a gradual decrease in urine volume and no significant improvement in fluid overload. Platelet count was $3 \times 10^{9} / \mathrm{L}$, and peritoneal effusion culture was positive for Enterobacter aerogenes and Pseudomonas ae-
Zhang/Yan Tang/Liu/Cai/Chan/Yang/ Chang/Wei/Liu/Yao/Wang/Marshall 
Table 1. Treatment details and outcomes

\begin{tabular}{|c|c|c|c|c|}
\hline & Case 1 & Case 2 & Case 3 & Case 4 \\
\hline History & $\begin{array}{l}\text { - 66-year-old man } \\
\text { - Necrotizing fasciitis } \\
\text { (Gram-positive cocci) } \\
\text { - Infection spread } \rightarrow \\
\text { multiple amputations; } \\
\text { multiorgan failure with } \\
\text { anuric AKI } \\
\text { - Acinetobacter baumannii } \\
\text { was found later from blood } \\
\text { culture and intraoperative } \\
\text { specimen }\end{array}$ & $\begin{array}{l}\text { - } 51 \text {-year-old man } \\
\text { - Abdominal mass } \\
\text { with gastric fistula } \\
\text { - Surgical removal } \rightarrow \\
\text { septic shock, MODS, } \\
\text { myelosuppression, } \\
\text { hypoproteinemia, anuric }\end{array}$ & $\begin{array}{l}\text { - 52-year-old man } \\
\text { - Fever, oliguria, } \\
\text { diaphragmatic hernia } \\
\text { - Surgical removal } \rightarrow \\
\text { conditions worsened } \\
\text { with sepsis, hemodynamic } \\
\text { instability, and AKI }\end{array}$ & $\begin{array}{l}\text { - 26-year-old man } \\
\text { - Severe acute pancreatitis, } \\
\text { sepsis, MODS, lower } \\
\text { gastrointestinal tract } \\
\text { bleeding, hypovolemic } \\
\text { shock, acute renal failure, } \\
\text { bilateral pneumonia, } \\
\text { paralytic ileus, and } \\
\text { hyperlipidemia } \rightarrow \text { surgery }\end{array}$ \\
\hline oXiris prescription* & $\begin{array}{l}\mathrm{CVVH}(25 \mathrm{~mL} / \mathrm{kg} / \mathrm{h} \text {; } \\
\text { no additional anticoagulant })\end{array}$ & $\begin{array}{l}\text { CVVHDF }(30-35 \mathrm{~mL} / \mathrm{kg} / \mathrm{h} \text {; } \\
\text { no additional anticoagulant) }\end{array}$ & $\begin{array}{l}\text { CVVH }(43 \mathrm{~mL} / \mathrm{kg} / \mathrm{h} \text {; } \\
\text { citrate) }\end{array}$ & $\begin{array}{l}\text { CVVH }(40 \mathrm{~mL} / \mathrm{kg} / \mathrm{h} ; \text { no } \\
\text { additional anticoagulant })\end{array}$ \\
\hline \multicolumn{5}{|l|}{$\begin{array}{l}\text { Outcomes parameters (before and } \\
\text { after oXiris initiation) }\end{array}$} \\
\hline Serum creatinine, $\mu \mathrm{moI} / \mathrm{L}$ & $\begin{array}{l}289 \rightarrow 161 \text { ( } 48 \mathrm{~h} \text { after } \\
\text { oXiris termination) }\end{array}$ & $98 \rightarrow 90$ & $436 \rightarrow 84$ & $452 \rightarrow 111$ \\
\hline Urine output, $\mathrm{mL} / \mathrm{h}$ & $\begin{array}{l}<50 \rightarrow<20 \text { (in the first } \\
12 \mathrm{~h} \text { of oXiris termination) } \rightarrow \\
>50 \text { (after } 12 \mathrm{~h} \text { of oXiris } \\
\text { termination) }\end{array}$ & $<50 \rightarrow 250$ & N/A & $<50$ \\
\hline Lactate, $\mathrm{mmol} / \mathrm{L}$ & $8.1 \rightarrow 4.9$ & $14.5 \rightarrow 4.3$ & $2.4 \rightarrow 0.9$ & $1.4 \rightarrow 1.1$ \\
\hline Norepinephrine dose, $\mu \mathrm{g} / \mathrm{kg} / \mathrm{min}$ & $0.9 \rightarrow 0.3$ & $1.5 \rightarrow 0$ & $1.0 \rightarrow 0.07$ & $0.55 \rightarrow 0.1$ \\
\hline PCT & N/A & $100 \rightarrow 18$ & $30 \rightarrow 2$ & $>200 \rightarrow 76$ \\
\hline SOFA score & $16 \rightarrow 14$ & $15 \rightarrow 12$ & $16 \rightarrow 9$ & $14 \rightarrow 13$ \\
\hline Duration per oXiris filter, $\mathrm{h}$ & 16 & 12 & 24 & $14,36,12$ and 18 ( 4 sets) \\
\hline
\end{tabular}

ruginosa. CRRT with oXiris was initiated on September 18 (Table 1; Appendix 1). After 3 days, urine output returned to 200- $250 \mathrm{~mL} / \mathrm{h}$, lactate decreased, fluid balance improved, and norepinephrine was no longer required. Platelet level was not affected by oXiris, and coagulation was not observed during the $12 \mathrm{~h}$ of heparin-free treatment. He was subsequently treated with conventional CRRT for approximately 3 weeks. After 71 days of ICU treatment, MODS caused by septic shock was cured, and the patient was transferred out of the ICU.

\section{Case 3}

A 52-year-old man was admitted on October 9, 2017, after suffering from abdominal pain for 13 days. He had fever and oliguria and had been in a minimally conscious state for 2 days. Surgery was performed on a suspected case of diaphragmatic hernia. One week postsurgery, he experienced fever, decreased urine output, decreased blood pressure, increased pulse rate, and cold limbs and remained in a minimally conscious state, with no improvement after norepinephrine infusion. On October 22, he was transferred to the ICU, where surgical wound care continued. Laboratory tests revealed elevated white blood cells, platelets $199 \times 10^{9} / \mathrm{L}$, lactic acid $4.4 \mathrm{mmol} / \mathrm{L}$, and creatinine $436 \mu \mathrm{mol} / \mathrm{L}$. The preliminary diagnosis was sepsis with abdominal infection, enterogenous infection, and grade 3 AKI.

Three hours later, conventional CRRT was initiated as a result of anuria and hemodynamic instability. He was switched to oXiris 2 days later (Table 1; Appendix 1), after which norepinephrine was reduced from 1 to $0.22 \mu \mathrm{g} / \mathrm{kg} / \mathrm{min}$, with further reduction to $0.07 \mu \mathrm{g} / \mathrm{kg} / \mathrm{min} 24 \mathrm{~h}$ later. The oXiris filter was replaced after $24 \mathrm{~h}$, and he was withdrawn from norepinephrine $48 \mathrm{~h}$ later. While receiving treatment with oXiris, his condition improved significantly. He was discharged on November 7 .

\section{Case 4}

A 26-year-old man was admitted on December 10, 2017, complaining of abdominal pain and distension for the past 22 days. $\mathrm{He}$ was diagnosed with severe acute pancreatitis, sepsis, MODS, lower gastrointestinal tract bleeding, hypovolemic shock, acute renal failure, bilateral pneumonia, paralytic ileus, and hyperlipidemia. $\mathrm{He}$ was treated with antibiotics, mechanical ventilation, CRRT, and blood transfusion, but his condition did not improve. On December 10, he was transferred to the ICU with creatinine $452 \mu \mathrm{mol} / \mathrm{L}$. Conventional CRRT was initiated, and abdominal paracentesis was performed 2 days later. On December 18, his condition progressed with abdominal distention. Abdominal computed tomography suggested gastrointestinal perforation and surgery was performed. EBP with oXiris was initiated postsurgery (Table 1; Appendix 1).

Four sets of oXiris were used, all without additional heparin anticoagulant. Coagulation occurred after 14, 36, and $12 \mathrm{~h}$ for the first, second, and third sets, respectively. Coagulation for the fourth set occurred after $18 \mathrm{~h}$, but it was suspected to be related to plasma transfusion. While on treatment with oXiris, oxygenation index improved significantly, and albumin was only minimally affected. The suspected cause of progressive decline in platelet count 
was related to overall worsening of his condition and unrelated to use of oXiris.

Eventually, oXiris was discontinued because of low platelet count and he received platelet infusion. Ascitic fluid culture revealed infections with multidrug-resistant bacteria and fungi. On December 27, his condition further deteriorated. He declined further treatment for financial reasons and was discharged.

\section{Discussion}

\section{Overview}

We present 4 cases of sepsis-induced AKI patients who received renal replacement treatment with oXiris at Tier 1 hospitals in China, to gain further insights into the use of oXiris for the stabilization of critically ill patients. Practical aspects from these cases are summarized below.

\section{Early Intervention and Good Control}

of Infection Source

Current recommendations for management of bacterial-induced sepsis is to provide antibiotic administration within $3 \mathrm{~h}$ of suspected sepsis [12,15-18]. In addition to early and targeted intervention to control the infection source, there is renewed interest in the role of endotoxin and cytokine removal for improving outcomes in critically ill patients $[19,20]$. The above cases demonstrated stabilization of the patients' hemodynamics and biochemical parameters with adequate infection source control and the early use of oXiris within 6-24 h of suspected sepsis.

Furthermore, oXiris should not be used to delay or replace infection source control. These cases illustrate that oXiris should be used as an adjuvant therapy in the management of sepsis. Septic patients require appropriate surgical and pharmacological interventions to manage organ dysfunction and infection. Similarly, while these cases demonstrated that oXiris can provide hemodynamic stability for the septic AKI patient, this may not have been possible if the infection source control was inadequate. Clearance of antibiotics during CRRT should also be monitored closely so that dosage adjustments can be made when necessary.

It should be noted that response to oXiris may differ in septic patients infected by Gram-positive versus Gramnegative bacteria, as endotoxin is only produced by Gram-negative bacteria $[13,21]$. However, endotoxemia can also occur in patients with Gram-positive infections, potentially linked to the translocation of normal gut flora, which comprises mainly Gram-negative bacteria [22]. Therefore, endotoxin removal will likely benefit all patients suffering from bacterial-induced sepsis. However, further research will be helpful in elucidating potential differences in endotoxin removal effectiveness and outcomes between different bacterial infection sources.

\section{Indicators of Treatment Initiation with oXiris}

To date, none of the contested biomarkers for sepsis are perfect. For example, procalcitonin has an early and sustained response profile after infection, and its detection assay is rapid and widely available, but the sensitivity and specificity of current assays are, on average, only 77 and $79 \%$, respectively $[23,24]$. In contrast, endotoxins are elevated transiently during the acute phase of an infection, and detection assays with high specificity are not widely available [21]. Elevated endotoxin can be induced by a number of triggers, and its short detection window usually precedes the patient's presentation to the ICU.

Although the majority of studies to date indicate a lack of clinical improvement in critically ill patients with AKI after removal of cytokines through hemofiltration [19], the studies demonstrating positive results should not be disregarded. The paucity of studies demonstrating positive outcomes after EBP initiation may, at least in part, be linked to patient heterogeneity, the complexity of each case, and the experience of the managing physician, affecting treatment factors such as initiation time, which cannot be standardized in the absence of indicative biomarkers. Short of definitive biomarkers to gauge the ideal EBP initiation time for septic AKI patients, clinical judgment is critical for determining the optimal time for initiating EBP with devices such as oXiris. Presence of hyperinflammatory state and/ or hemodynamic instability with use of vasopressor in patients with septic AKI should be considered for early EBP initiation with oXiris, together with infection source control and standard sepsis care, without waiting for diagnostic confirmation of abnormal biomarker levels.

\section{Experience with oXiris Performance}

Based on clinical experience from the cases reported here, patients with high risk of bleeding can use oXiris without anticoagulation for up to $36 \mathrm{~h}$ with no implications on serum protein levels and platelet count. To avoid adsorption saturation, it is recommended in the product label to change the filter set once every $24 \mathrm{~h}$ to ensure filter performance, with an upper limit of $72 \mathrm{~h}$ and/or a maximum process volume of $780 \mathrm{~L}$ of blood, whichever occurs first [5].

\section{Optimal Discontinuation Time for oXiris}

While specific guidance and clinical indicators for oXiris discontinuation could be helpful, they are not available; therefore, discontinuation should be personal-
Zhang/Yan Tang/Liu/Cai/Chan/Yang/ Chang/Wei/Liu/Yao/Wang/Marshall 
ized and determined on a case-by-case basis, based on the initial treatment goals and the patient's condition. Potential discontinuation indicators gathered from these cases include improvement in hemodynamics with reduction of vasopressor dose, reduction in lactate and proinflammatory markers, and improvement in urine output.

\section{Conclusions and Next Steps}

oXiris should be used early in the treatment of septic AKI patients as an adjuvant therapy with good infection source control. The optimal timing of initiation, duration of therapy, and target population (Gram-negative or Gram-positive bacteremia) will warrant further studies.

Practical aspects gathered from these cases could also be helpful for developing appropriate inclusion criteria and study designs for future case-control studies and randomized controlled studies in Asian patients, which should be carefully designed with standardized treatment initiation time, standardized dosing increments, and defined secondary endpoints indicating clinical improvement. Data from such trials would provide critical evidence to inform the clinical use of oXiris in septic AKI management.

\section{Acknowledgments}

The authors would like to thank the patients and their families for their contribution to this publication. Writing assistance was provided by Carmen Chu from Mudskipper Business Consulting (Shanghai) Limited, funded by Baxter (China).

\section{Disclosure Statement}

M.R.M., M.W., Q.Y., and X.L. are employees of Baxter Healthcare Corporation and hold Baxter stocks. All other authors have no conflicts of interest to declare.

\section{Funding Source}

This research was not supported by any grants from funding agencies in the public, commercial, or not-for-profit sectors.

\section{Ethical Approval}

All subjects enrolled in this research have given their informed consent.

\section{Appendix}

oXiris Prescription Details

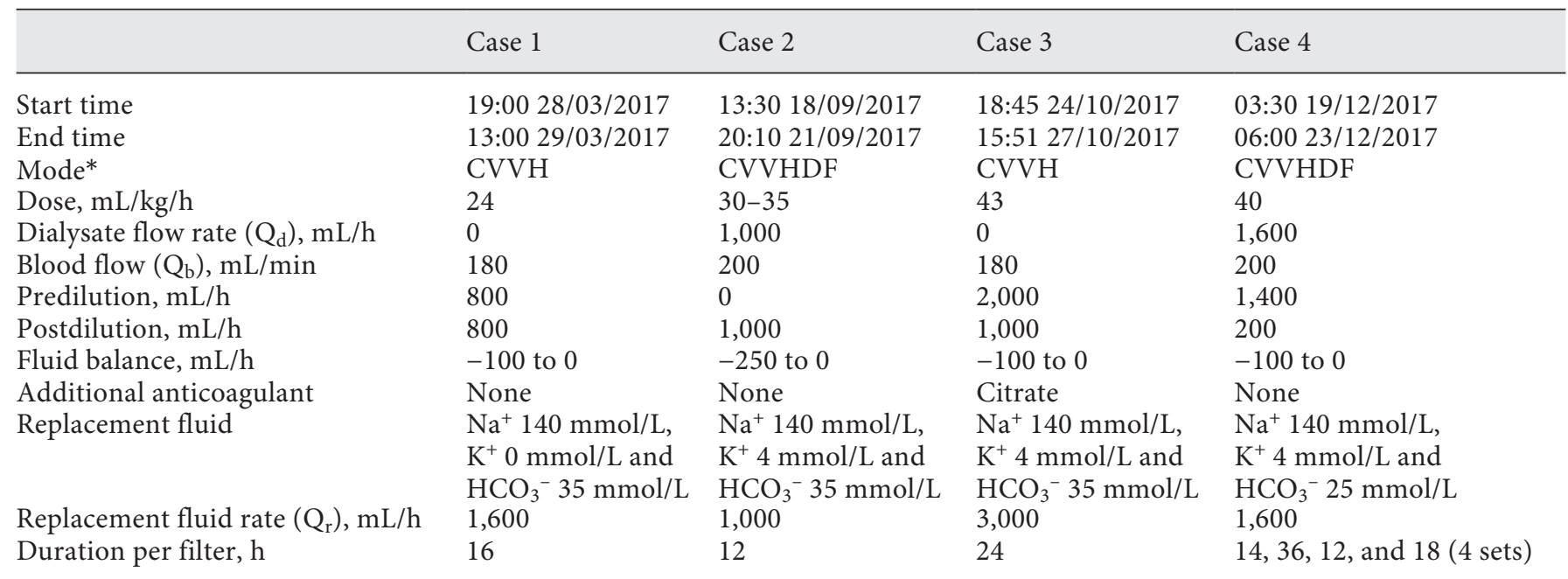

* CVVH, continuous venovenous hemofiltration; CVVHDF, continuous venovenous hemodiafiltration.

Case Series on oXiris for Septic AKI

Patients in the Asian Population
Blood Purif 2019;47(suppl 3):45-50 DOI: $10.1159 / 000499357$ 


\section{References}

1 Case J, Khan S, Khalid R, Khan A. Epidemiology of acute kidney injury in the intensive care unit. Crit Care Res Pract. 2013;2013: 479730.

2 Alobaidi R, Basu RK, Goldstein SL, Bagshaw SM. Sepsis-associated acute kidney injury. Semin Nephrol. 2015 Jan;35(1):2-11.

3 Honore PM, Jacobs R, Joannes-Boyau O, De Regt J, Boer W, De Waele E, et al. Septic AKI in ICU patients. diagnosis, pathophysiology, and treatment type, dosing, and timing: a comprehensive review of recent and future developments. Ann Intensive Care. 2011 Aug;1(1):32.

4 Gambro Industries. oXiris preclinical data and clinical evaluation. Data on file; 2007.

5 Gambro Industries. oXirisTM Instructions for use. 2015

6 Thomas M, Moriyama K, Ledebo I. AN69: evolution of the world's first high permeability membrane. Contrib Nephrol. 2011;173: 119-29.

7 Imahase H, Sakamoto Y, Kusunose M, Koami $\mathrm{H}$, Nishimura Y, Goto A, et al. Examination of blood filtration membrane removal ability of HMGB1. Crit Care 2012;16(Suppl 3):P10.

8 Caravetta P, Lappa A, Menichetti A, Barchetta R, Candidi F, Falco M, Turani F. Continuous renal replacement therapy combined with endotoxins removal in septic patients: a pilot study. International Conference on Continuous Renal Replacement Therapies. San Diego, CA, USA; 12-15 February 2013, abstract 53.

9 Turani F, Candidi F, Barchetta R, Grilli E, Belli A, Papi E, et al. Continuous renal replacement therapy with the adsorbent membrane oXiris in septic patients: a clinical experience. Crit Care. 2013;17 Suppl 2:P63.
10 Malard B, Lambert C, Kellum JA. In vitro comparison of the adsorption of inflammatory mediators by blood purification devices. Intensive Care Med Exp. 2018 May;6(1):12.

11 Singer M, Deutschman CS, Seymour CW, Shankar-Hari M, Annane D, Bauer M, et al. The Third International Consensus Definitions for Sepsis and Septic Shock (Sepsis-3). JAMA. 2016 Feb;315(8):801-10.

12 American College of Chest Physicians/Society of Critical Care Medicine Consensus Conference: definitions for sepsis and organ failure and guidelines for the use of innovative therapies in sepsis. Crit Care Med. 1992 Jun; 20(6):864-74

13 Adamik B, Smiechowicz J, Zielinski S, Kübler A. Use of extracorporeal endotoxin elimination therapy for septic shock. Crit Care Med. 2013;17 Suppl 2:66

14 Baxter China. Data on file; 2018

15 Nguyen HB, Jaehne AK, Jayaprakash N, Semler MW, Hegab S, Yataco AC, et al. Early goaldirected therapy in severe sepsis and septic shock: insights and comparisons to ProCESS, ProMISe, and ARISE. Crit Care. 2016 Jul;20(1): 160.

16 Weisberg A, Park P, Cherry-Bukowiec JR. Early Goal-Directed Therapy: The History and Ongoing Impact on Management of Severe Sepsis and Septic Shock. Surg Infect (Larchmt). 2018 Feb/Mar;19(2):142-6.

17 Rivers E, Nguyen B, Havstad S, Ressler J, Muzzin A, Knoblich B, et al.; Early Goal-Directed Therapy Collaborative Group. Early goal-directed therapy in the treatment of severe sepsis and septic shock. N Engl J Med. 2001 Nov;345(19):1368-77.
18 Dellinger RP, Levy MM, Carlet JM, Bion J, Parker MM, Jaeschke R, et al. Surviving Sepsis Campaign: international guidelines for management of severe sepsis and septic shock: 2008 . Intensive Care Med. 2008 Jan;34(1):17-60

19 Atan R, Peck L, Prowle J, Licari E, Eastwood GM, Storr M, et al. A Double-Blind Randomized Controlled Trial of High Cutoff Versus Standard Hemofiltration in Critically Ill Patients With Acute Kidney Injury. Crit Care Med. 2018 Oct;46(10):e988-94.

20 Dellinger RP, Bagshaw SM, Antonelli M, Foster DM, Klein DJ, Marshall JC, et al.; EUPHRATES Trial Investigators. Effect of Targeted Polymyxin B Hemoperfusion on 28Day Mortality in Patients With Septic Shock and Elevated Endotoxin Level: The EUPHRATES Randomized Clinical Trial. JAMA. 2018 Oct;320(14):1455-63.

21 Reinhart K, Bauer M, Riedemann NC, Hartog CS. New approaches to sepsis: molecular diagnostics and biomarkers. Clin Microbiol Rev. 2012 Oct;25(4):609-34.

22 Marshall JC, Foster D, Vincent JL, Cook DJ, Cohen J, Dellinger RP, et al.; MEDIC study. Diagnostic and prognostic implications of endotoxemia in critical illness: results of the MEDIC study. J Infect Dis. 2004 Aug;190(3): 527-34.

23 Becker KL, Snider R, Nylen ES. Procalcitonin assay in systemic inflammation, infection, and sepsis: clinical utility and limitations. Crit Care Med. 2008 Mar;36(3):941-52.

24 Wacker C, Prkno A, Brunkhorst FM, Schlattmann P. Procalcitonin as a diagnostic marker for sepsis: a systematic review and meta-analysis. Lancet Infect Dis. 2013 May;13(5):426-35. 